\title{
Effectiveness of a quality improvement intervention targeting cardiovascular risk factors: are patients responsive to information and encouragement by mail or post?
}

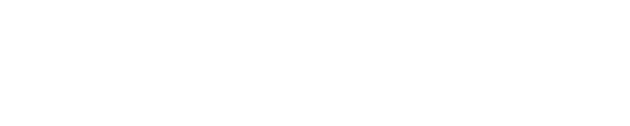

Ellie Senesael

Liesbeth Borgermans

Erwin Van De Vijver

Dirk Devroey

Department of Family Medicine, Vrije Universiteit Brussel, Brussels, Belgium
Correspondence: Dirk Devroey Department of Family Medicine, Vrije Universiteit Brussel, Laarbeeklaan 103,

B-1090 Brussels, Belgium

$\mathrm{Tel}+32247743$ I I

Fax +32 24774301

Email dirk.devroey@vub.ac.be
Introduction: There is important evidence on the beneficial effects of treatment of cardiovascular risk factors in terms of morbidity and mortality, but important challenges remain in motivating patients to adhere to their treatment regimen. This study aimed to describe the effectiveness of a quality improvement intervention that included information and regular encouragement by email or letter on cardiovascular risk factors for patients at high risk for cardiovascular disease.

Methods: This randomized single-blind study included patients of both sexes aged between 45 and 80 years old who had increased cardiovascular risk. Patients were randomly allocated to either a usual care group (UCG) or advanced care group (ACG). Patients in the UCG received regular care while patients in the ACG received usual care plus regular information and encouragement on cardiovascular risk factors by email or letter. Visits for both groups were planned at 0,3 , and 6 months. The outcome measures were blood pressure, weight, body mass index (BMI), waist circumference (WC), and smoking status.

Results: Out of 178 eligible patients from one single primary care practice, 55 participated in the study, three of whom dropped out. After 6 months, there was a significant decrease in mean systolic and diastolic blood pressure in the UCG and ACG $(P<0.05)$. The decreases were already significant after 3 months, except for systolic blood pressure in the UCG. There was also a significant increase in the proportion of patients who met the target values for blood pressure in the UCG and ACG. There was a nonsignificant decrease of the average weight in the ACG, but significantly more patients lost weight in the UCG $(P=0.02)$. BMI, WC, and smoking status did not change in either group.

Conclusion: This study found that there was a significant decrease of systolic and diastolic blood pressure in both study groups. Weight, BMI, WC, and smoking did not improve in either group. Information on cardiovascular risk factors and encouragement by means of letters or email did not provide additional benefits. Thus, effective patient empowerment probably requires more behaviorally sophisticated support to increase self-management, self-efficacy, and self-esteem in patients.

Keywords: cardiovascular risk, tele-health, lifestyle, family medicine

\section{Introduction}

Cardiovascular diseases can lead to major complications such as myocardial infarction and cerebrovascular accident and continue to be the leading cause of mortality in Europe. ${ }^{1-5}$ There is compelling evidence on the effectiveness of preventive interventions (eg, interventions to reduce tobacco consumption, obesity, physical inactivity, and harmful alcohol use $)^{5,6}$ but only a limited number of patients at risk reach 
treatment targets. ${ }^{6-11}$ Medication is indicated when targets for blood pressure and cholesterol are not achieved with lifestyle changes. ${ }^{5}$ There is no consensus in Belgium on the degree of responsibility that should be placed on the individual in the prevention of chronic illnesses, as this depends on cultural views regarding the role of the state and individual autonomy. However, there is increasing recognition that reduced risk and improved outcomes cannot depend solely on the actions of health professionals but are also contingent on the individual's own actions. Most chronic condition care is provided by the individual patient themselves. The successful management of chronic illnesses requires patients to make multiple lifestyle changes as part of an intensive, complex, and coordinated therapeutic regimen aimed at reducing the risk of complications often associated with the disease. The difficulty in creating and sustaining these lifestyle behavior changes is a major stumbling block towards achievement of the desired therapeutic goal. ${ }^{12}$ Further, a Belgian study demonstrated that many patients were not even aware of their cardiovascular risk factors. ${ }^{13}$

Available evidence supports the fact that family physicians are key players in any chronic illness management strategy, as they play an essential role in chronic disease prevention, identification, and management. They are also key players because they are at the frontline and constitute the gateway into the health care system. As such, family physicians have an essential role to play in influencing and changing patient behavior. ${ }^{14}$ However, a Belgian study showed that a short awareness intervention embedded within usual care did not result in a reduction of cardiovascular risk in patients over a 7 -year period. ${ }^{15}$

There is substantial evidence on the effectiveness of selfmanagement interventions in patients with chronic illnesses on the outcomes of care. ${ }^{16,17}$ The World Health Organization defines self-management as "the activities individuals, families and communities undertake with the intention of enhancing health, preventing disease and restoring health." 18 The overall goal of self-management support is for patients and their families to understand the relationship between behavior, health, and disease and to be able to take appropriate actions with the help of the health system. Although there is consensus that self-management support involves a patient-centered collaborative approach, the concept of "self-management" is frequently imprecisely defined and understood to capture a broad range of activities including patient education for disease complications and management; alcohol, food intake, and exercise advice; and lifestyle visits. ${ }^{19}$ Patient education and/or promotion of self-management thus encompasses many modes of instruction. There is important evidence from quality improvement programs that apply information and communication technologies (support by phone, teleconference, websites, and text messaging) and that target adherence to medication regimens and healthy lifestyles in different patient groups. These programs have demonstrated positive results for both clinical (eg, mortality, survival rates, hemoglobin A1c levels, blood pressure) and nonclinical parameters (eg, missed appointments, reduction in contact with physicians) as well as an overall reduction in cardiovascular risk factors. ${ }^{20-23}$

This study aimed to describe the influence of regular information and encouragement by email or letter on cardiovascular risk factors in patients at risk for cardiovascular disease development. We hypothesized that our interventions would cause a significant decrease in cardiovascular risk factors in the intervention group compared with the usual care group.

\section{Methods}

\section{Study population and design}

Patients were recruited in a primary care practice in Beersel, Belgium. Patients of both sexes aged between 45 and 80 years old were eligible to enter the study if they had an increased cardiovascular risk (at time of recruitment or projected at the age of 65) and if they were smokers, hypertensive, or overweight. The cut-off value for blood pressure was 160 over $90 \mathrm{mmHg}$ and for overweight, a body mass index (BMI) of $>25$. Eligible patients were invited to participate by letter. After confirming their willingness to participate, they were contacted by phone to arrange an appointment.

We opted for a randomized single-blind design. Participants were randomized during their first visit to either a usual care group (UCG) or an advanced care group (ACG). A minimization technique was applied, taking into account age, sex, and blood pressure values and to ensure an equal distribution of men and women, young and old patients, and patients with mild and severe hypertension.

\section{Intervention}

Patients in the UCG received usual care whereas, in addition to usual care, patients in the $A C G$ received information, encouragement, and personal tips sent by post or email every 2 weeks for a period of 6 months. In the first round, information was provided to ACG patients on determinants of cardiovascular risk, how cardiovascular risk was estimated, and the implications of cardiovascular risk on health and daily life. In the next round, information was provided on hypertension, how it evolves, and what patients can do about it in terms of adapting their 
lifestyles. Following this, specific letters/emails were sent on cholesterol followed by physical exercise and healthy eating. Patients were informed of the risks of obesity and sedentary lifestyles and advised about BMI and their own individual cardiovascular risk. Finally, information was provided on smoking cessation, diabetes, and their own blood pressure.

The aim of the intervention was to empower patients. Research has shown that patient empowerment directly influences the degree to which treatment goals will be achieved as well as the level of patient satisfaction. ${ }^{24}$

\section{Data collection}

For each participant, the family physician completed a form at the first visit. In addition, a clinical examination was performed.

Data were collected on sex, age, personal history, smoking status, latest serum values of total cholesterol (TC), high-density lipoprotein cholesterol (HDL-C), low density lipoprotein cholesterol (LDL-C), triglycerides, glucose, hemoglobin A1c, and treatment for diabetes, obesity, hypertension, and dyslipidemia. From the clinical examination, systolic and diastolic blood pressure, heart rate, height, weight, BMI, and waist circumference (WC) were recorded.

Participants in both groups returned after 3 and 6 months for their smoking status; current treatment for diabetes, obesity, hypertension, and dyslipidemia; and systolic and diastolic blood pressure, heart rate, weight, BMI, and WC to be assessed and details of these to be recorded.

\section{Ethics committee approval and informed consent}

The Ethics Committee of the University Hospital of the Vrije Universiteit Brussel approved the study protocol in April 2011. Participants were informed about the study's aim and the methods prior to their inclusion. All participants signed an informed consent.

\section{Statistical analyses}

For the statistical analyses and processing, $\operatorname{SPSS}^{\circledR}$ (v 20; IBM, Armonk, NY, USA) was used. The chi-square test was used to identify differences between the intervention group and the control group. Fisher's exact test was used for subgroups with fewer than ten members. The $t$-test was used to compare continuous variables. The level of significance was determined at 0.05 . The three cardiovascular risk categories were determined according to the European Systematic COronary Risk Evaluation (SCORE) Risk Charts for Belgium.

\section{Results}

\section{Baseline characteristics}

In total, 178 patients met the inclusion criteria for the study, of whom 57 agreed to participate; 55 patients were included during their first visit, 53 returned after 3 months, and 52 completed the 6-month study ( 30 men and 22 women). The baseline characteristics for the intervention and control groups are compared in Table 1. No significant differences were observed between the groups.

\section{Lifestyle changes}

No single patient in the UCG or ACG ceased smoking and no significant changes in body weight were detected in either group (Table 2). After 6 months: the average weight of participants in both groups showed a slight nonsignificant decrease - minus $700 \mathrm{~g}$ in the ACG $(P=0.90)$ and minus $400 \mathrm{~g}$ in the $\operatorname{UCG}(P=0.93) ; 14$ participants in the ACG and seven participants in the UCG lost at least $1 \mathrm{~kg}(P=0.09)$; the average BMI showed a slight decline, but this decrease was not significant $(P=0.88$ in the ACG and $P=0.92$ in the UCG); and the average WC decreased by $2.9 \mathrm{~cm}$ in the ACG and $2.3 \mathrm{~cm}$ in the UCG, but the difference was not significant ( $P=0.54$ and $P=0.58$, respectively).

Table I Baseline patient characteristics, concomitant diseases, and medications

\begin{tabular}{|c|c|c|c|}
\hline & $\begin{array}{l}\text { Advanced care } \\
(n=26)\end{array}$ & $\begin{array}{l}\text { Usual care } \\
(n=26)\end{array}$ & $P$ value \\
\hline \multicolumn{4}{|l|}{ Baseline characteristics } \\
\hline Mean age, in years (SD) & $62(10)$ & $63(9)$ & 0.84 \\
\hline Men, n (\%) & $17(65)$ & $13(50)$ & 0.26 \\
\hline Women, n (\%) & $9(35)$ & $13(50)$ & $0.40 *$ \\
\hline Women aged over $50, \mathrm{n}(\%)$ & $9(100)$ & II (85) & $0.68^{*}$ \\
\hline $\mathrm{TC}$, in $\mathrm{mg} / \mathrm{dL}(\mathrm{SD})$ & $202(38)$ & $198(30)$ & 0.68 \\
\hline $\mathrm{HDL}-\mathrm{C}$, in $\mathrm{mg} / \mathrm{dL}(\mathrm{SD})$ & $60(26)$ & $63(12)$ & 0.60 \\
\hline $\mathrm{TC} / \mathrm{HDL}-\mathrm{C}$, in mg/dL (SD) & $4.2(3.1)$ & $3.3(0.9)$ & 0.16 \\
\hline \multicolumn{4}{|c|}{ Concomitant diseases, n (\%) } \\
\hline Myocardial infarction & $0(0.0)$ & $\mathrm{I}(3.8)$ & $1.00 *$ \\
\hline Stroke & $2(7.7)$ & $\mathrm{I}(3.8)$ & $1.00 *$ \\
\hline TIA & $\mathrm{I}(3.8)$ & $2(7.7)$ & $1.00 *$ \\
\hline Vascular disease & $0(0.0)$ & $\mathrm{I}(3.8)$ & $1.00 *$ \\
\hline Diabetes & $2(7.7)$ & $4(15)$ & $0.66^{*}$ \\
\hline Angor & $0(0.0)$ & $0(0.0)$ & $1.00 *$ \\
\hline CABG & $2(7.7)$ & $\mathrm{I}(3.8)$ & $1.00 *$ \\
\hline PTCA & I (3.7) & $\mathrm{I}(3.8)$ & $1.00 *$ \\
\hline \multicolumn{4}{|c|}{ Medication at baseline, $\mathrm{n}(\%)$} \\
\hline Aspirin & $7(27)$ & $7(27)$ & $1.00 *$ \\
\hline Antidiabetic drugs & $2(7.7)$ & $4(15)$ & $0.66 *$ \\
\hline Lipid-lowering drugs & $12(46)$ & $9(35)$ & $0.29 *$ \\
\hline Antihypertensive drugs & $15(58)$ & $16(62)$ & 0.78 \\
\hline
\end{tabular}

Note: *Fisher's exact test was used for subgroups of $<10$ members.

Abbreviations: CABG, coronary artery bypass graft; HDL-C, high-density lipoprotein cholesterol;PTCA, percutaneoustransluminal coronaryangioplasty;SD, standarddeviation; TC, total cholesterol; TIA, transient ischemic attack. 


\section{Blood pressure and heart rate}

During the course of the study, no significant difference in the systolic or diastolic blood pressure was detected between the ACG and the UCG (Table 2). In the ACG, we observed a significant decrease in systolic blood pressure $(12 \mathrm{mmHg}$ and $14 \mathrm{mmHg}$ after 3 and 6 months, respectively $[P=0.003$ and $P=0.001$, respectively]) (Figure 1). A similar significant decrease in systolic blood pressure was also observed in the UCG $(14 \mathrm{mmHg}$ and $13 \mathrm{mmHg}$ after 3 and 6 months, respectively $[P=0.001$ in both cases $])$. In the ACG, we observed a significant decrease in diastolic blood pressure of $8 \mathrm{mmHg}$ both after 3 and 6 months $(P=0.002$ in both cases) (Figure 2). Again, there was a significant decrease in diastolic blood pressure of $7 \mathrm{mmHg}$ and $8 \mathrm{mmHg}$ after 3 and 6 months, respectively $(P=0.008$ and $P=0.004$, respectively).

Further, during the course of the study, no significant difference in heart rate was detected between the two groups and, after 6 months, there was no decrease in heart rate in the ACG $(P=0.23)$ or the UCG $(P=0.72)$.

Table 2 Patient outcome parameters

\begin{tabular}{|c|c|c|c|}
\hline & $\begin{array}{l}\text { Advanced care } \\
(\mathrm{n}=26)\end{array}$ & $\begin{array}{l}\text { Usual care } \\
(n=26)\end{array}$ & $P$ value \\
\hline \multicolumn{4}{|c|}{ Smokers, n (\%) } \\
\hline 0 months & $3(12)$ & $4(15)$ & $1.00 *$ \\
\hline 3 months & $3(12)$ & $4(15)$ & $1.00 *$ \\
\hline 6 months & $3(12)$ & $4(15)$ & $1.00 *$ \\
\hline \multicolumn{4}{|c|}{ Mean weight, kg (SD) } \\
\hline 0 months & $84.5(20.4)$ & $80.8(15.3)$ & 0.46 \\
\hline 3 months & $83.9(20.6)$ & $80.3(16.0)$ & 0.48 \\
\hline 6 months & $83.8(21.1)$ & $80.4(16.1)$ & 0.52 \\
\hline \multicolumn{4}{|c|}{ Body mass index, $\mathrm{kg} / \mathrm{m}^{2}$ (SD) } \\
\hline 0 months & $28.4(5.7)$ & $28.1(4.2)$ & 0.83 \\
\hline 3 months & $28.2(5.9)$ & $28.0(4.4)$ & 0.94 \\
\hline 6 months & $28.1(6.1)$ & $28.0(4.5)$ & 0.97 \\
\hline \multicolumn{4}{|c|}{ Waist circumference, cm (SD) } \\
\hline 0 months & $102.6(16.3)$ & $99.6(14.8)$ & 0.50 \\
\hline 3 months & $100.8(16.2)$ & $99.0(14.9)$ & 0.68 \\
\hline 6 months & $99.7(17.0)$ & $97.4(14.5)$ & 0.59 \\
\hline \multicolumn{4}{|c|}{ Systolic blood pressure, mmHg (SD) } \\
\hline 0 months & $153(12)$ & $153(13)$ & 1.00 \\
\hline 3 months & $|4|(\mid 4)$ & $142(15)$ & 0.87 \\
\hline 6 months & $139(15)$ & $139(14)$ & 1.00 \\
\hline \multicolumn{4}{|c|}{ Diastolic blood pressure, mmHg (SD) } \\
\hline 0 months & $85(8)$ & $88(10)$ & 0.24 \\
\hline 3 months & $77(8)$ & $81(10)$ & 0.12 \\
\hline 6 months & $77(9)$ & $80(9)$ & 0.24 \\
\hline \multicolumn{4}{|c|}{ Heart rate, bpm (SD) } \\
\hline 0 months & $70(9)$ & $70(6)$ & 1.00 \\
\hline 3 months & $69(9)$ & $66(7)$ & 0.19 \\
\hline 6 months & $67(8)$ & $69(11)$ & 0.46 \\
\hline
\end{tabular}

Note: *Fisher's exact test was used for subgroups of $<10$ members. Abbreviation: SD, standard deviation.
Table 3 Proportion of patients with a low $(<5 \%)$, moderate $(5 \%-10 \%)$ and high $(\geq 10 \%)$ cardiovascular risk Systematic COronary Risk Evaluation (SCORE) at month 0, 3, and 6

\begin{tabular}{|c|c|c|c|}
\hline & $\begin{array}{l}\text { Advanced care } \\
(n=26)\end{array}$ & $\begin{array}{l}\text { Usual care } \\
(n=26)\end{array}$ & $P$ value \\
\hline \multicolumn{4}{|c|}{ SCORE at month $0, \mathrm{n}(\%)$} \\
\hline Low $(<5 \%)$ & $12(43)$ & $10(39)$ & 0.57 \\
\hline Moderate $(5 \%-10 \%)$ & $5(19)$ & $7(27)$ & $0.74 *$ \\
\hline High $(>10 \%)$ & $9(35)$ & $9(35)$ & $0.77^{*}$ \\
\hline \multicolumn{4}{|c|}{ SCORE at month $3, \mathrm{n}(\%)$} \\
\hline Low $(<5 \%)$ & $14(54)$ & $13(50)$ & 1.00 \\
\hline Moderate $(5 \%-10 \%)$ & $5(19)$ & $8(3 I)$ & $0.52 *$ \\
\hline High $(>10 \%)$ & $7(27)$ & $5(19)$ & $0.74 *$ \\
\hline \multicolumn{4}{|c|}{ SCORE at month 6, n (\%) } \\
\hline Low $(<5 \%)$ & $16(62)$ & $12(46)$ & 0.26 \\
\hline Moderate $(5 \%-10 \%)$ & $3(12)$ & $10(39)$ & $0.06 *$ \\
\hline High $(>10 \%)$ & $7(27)$ & $4(15)$ & $0.49 *$ \\
\hline
\end{tabular}

Notes: according to the European SCORE Risk Charts for Belgium; *Fisher's exact test was used for subgroups of $<10$ members.

\section{Target level attainment}

The number of patients in the ACG who attained a systolic blood pressure below $140 \mathrm{mmHg}$ (or $130 \mathrm{mmHg}$ for diabetics) after 6 months increased from one to twelve $(P=0.001)$ (Table 4). The number of patients with a diastolic blood pressure of less than $90 \mathrm{mmHg}$ (or $80 \mathrm{mmHg}$ for diabetics) increased from twelve to $23(P=0.001)$. A similar increase was noted in the UCG: the proportion of patients attaining the target for systolic blood pressure increased from zero to ten $(P=0.002)$ and from eight to 18 for diastolic blood pressure $(P=0.01)$. For systolic blood pressure, this significant increase was not seen in the UCG after 3 months $(P=0.24)$ whereas, in the ACG, the increase was already significant after 3 months $(P=0.01)$. For diastolic blood pressure, the differences between both groups were already significant after 3 months. The number of patients meeting the targets for both systolic and diastolic blood pressure increased significantly after 3 months in the ACG $(P=0.01)$ but not in the UCG $(P=0.49)$. After 6 months, the number of participants reaching the blood pressure targets (diastolic and systolic combined) increased in the ACG $(P=0.001)$ as well as in the UCG $(P=0.002)$.

The proportion of overweight or obese patients did not change over the 6-month study period in either group, while the proportion of patients with an increased WC increased over the 6-month study period but not significantly $(P=0.15$ and 0.77 in ACG and UCG, respectively).

\section{Risk evaluation}

After 6 months, the number of patients at low risk increased from 12 to 16 in the ACG (Table 3). However, the increase was not significant $(P=0.27)$. A similar nonsignificant increase 
Table 4 Blood pressure, body mass index, and waist circumference target level attainment at month 0,3 , and 6

\begin{tabular}{|c|c|c|c|}
\hline & $\begin{array}{l}\text { Advanced care } \\
(n=26)\end{array}$ & $\begin{array}{l}\text { Usual care } \\
(n=26)\end{array}$ & $P$ value \\
\hline \multicolumn{4}{|c|}{ Systolic blood pressure $<140 \mathrm{mmHg}$ (130 mmHg for diabetics), n (\%) } \\
\hline Month 0 & I (4) & $0(0)$ & $1.00 *$ \\
\hline Month 3 & $9(35)$ & $3(12)$ & $0.10^{*}$ \\
\hline Month 6 & $12(46)$ & $10(39)$ & 0.57 \\
\hline \multicolumn{4}{|c|}{ Diastolic blood pressure $<90 \mathrm{mmHg}$ (80 mmHg for diabetics), $\mathrm{n}(\%)$} \\
\hline Month 0 & $12(46)$ & $8(31)$ & $0.39 *$ \\
\hline Month 3 & $19(73)$ & $18(69)$ & 0.76 \\
\hline Month 6 & $23(89)$ & $18(69)$ & 0.09 \\
\hline \multicolumn{4}{|c|}{ Blood pressure < I40/90 mmHg (I30/80 mmHg for diabetics), n (\%) } \\
\hline Month 0 & I (4) & $0(0)$ & $1.00 *$ \\
\hline Month 3 & $9(35)$ & $2(8)$ & $0.05^{*}$ \\
\hline Month 6 & $12(46)$ & $9(35)$ & $0.57^{*}$ \\
\hline \multicolumn{4}{|c|}{ Body mass index $<25$ m/kg, $\mathrm{n}(\%)$} \\
\hline Month 0 & $6(23)$ & $7(27)$ & $1.00 *$ \\
\hline Month 3 & $7(27)$ & $7(27)$ & $0.75 *$ \\
\hline Month 6 & $7(27)$ & $9(35)$ & $0.76^{*}$ \\
\hline \multicolumn{4}{|c|}{ Body mass index < 30 m/kg, n (\%) } \\
\hline Month 0 & $17(65)$ & $16(62)$ & 0.77 \\
\hline Month 3 & $17(65)$ & $16(62)$ & 0.77 \\
\hline Month 6 & $17(65)$ & $16(62)$ & 0.77 \\
\hline \multicolumn{4}{|c|}{ Waist circumference $<102 \mathrm{~cm}$ for men or $<88 \mathrm{~cm}$ for women, $\mathrm{n}(\%)$} \\
\hline Month 0 & $7(27)$ & $9(35)$ & $0.76^{*}$ \\
\hline Month 3 & $10(39)$ & $10(39)$ & 1.00 \\
\hline Month 6 & $12(46)$ & $10(39)$ & 0.78 \\
\hline
\end{tabular}

Note: *Fisher's exact test was used for subgroups of $<10$ members.

was also observed in the UCG $(P=0.57)$. Similarly, in the moderate and high-risk groups, no significant changes were apparent after 3 and 6 months.

In the subgroup of patients with initial low cardiovascular risk, there was a significant increase in the number of patients in the ACG who met the targets for systolic blood pressure after 3 and 6 months $(P=0.002$ and $P=0.001$, respectively) and for diastolic blood pressure after 6 months $(P=0.02)$. For the endpoint of combined systolic and diastolic blood pressure targets a similar increase was observed after 3 and 6 months $(P=0.002$ and $P=0.001)$. For the patients in the $\mathrm{UCG}$, similar observations were made after 6 months: there was a significant increase in the number of patients with initial low cardiovascular risk who met the target of systolic $(P=0.001)$, diastolic $(P=0.02)$, and combined systolic and diastolic blood pressure $(P=0.001)$.

In the subgroup of patients with initial moderate cardiovascular risk, the number in the ACG who met the targets for systolic blood pressure had not changed after 6 months $(P=1.00)$. The same observation was made in the UCG. The number of patients who met the targets for diastolic blood pressure did not increase significantly after 6 months in the ACG $(P=0.20)$ or the UCG $(P=0.10)$. Similar observations were made for the combined systolic and diastolic blood pressure in both groups.

In the subgroup of patients with initial high cardiovascular risk, no significant changes were observed after 3 and 6 months in the ACG or the UCG.

\section{Discussion}

A total of 52 patients participated in this study and the drop-out rate for woman was greater than that for men. As a result, the ACG comprised fewer women, even though the participants were minimized by sex at the start of the study.

SCORE risks were determined at months 0 and 6 using the most recent values of TC and HDL-C. Between these times, no additional TC or HDL-C measurements could be performed. The SCORE risk was therefore calculated under the assumption that patients' lipid profiles had not changed over the course of these 6 months. However, it is reasonable to assume that lipid levels decreased during the study period, but, for local ethical and practical reasons, no new blood samples were taken.

\section{Weight loss}

We noticed a decrease in body weight in the ACG as well as in the UCG, but this decrease was too small to be statistically significant. This finding is not in line with other studies reporting that information and encouragement have a significant effect on body weight loss.

For example, a study in Baltimore, Maryland, USA showed that incentives and coaching through a study-specific website significantly improved weight loss in the intervention groups compared with the control group. ${ }^{22}$ Participants in that study had on average a much higher start weight than in our study and the trial duration was much longer (24 months) than ours, giving it higher power.

Another study comparing the influence of the Weight Watchers program with usual care showed significantly higher weight loss in the Weight Watchers group. ${ }^{19}$ The average start weight was approximately the same as in our study, but, again, the study duration was longer (12 months) - this may reveal an important weakness in our study design. Further, the intervention of the Weight Watchers program is also substantially different from our intervention.

A Dutch study compared the influence of information on lifestyle changes by telephone, email, or lifestyle brochures 


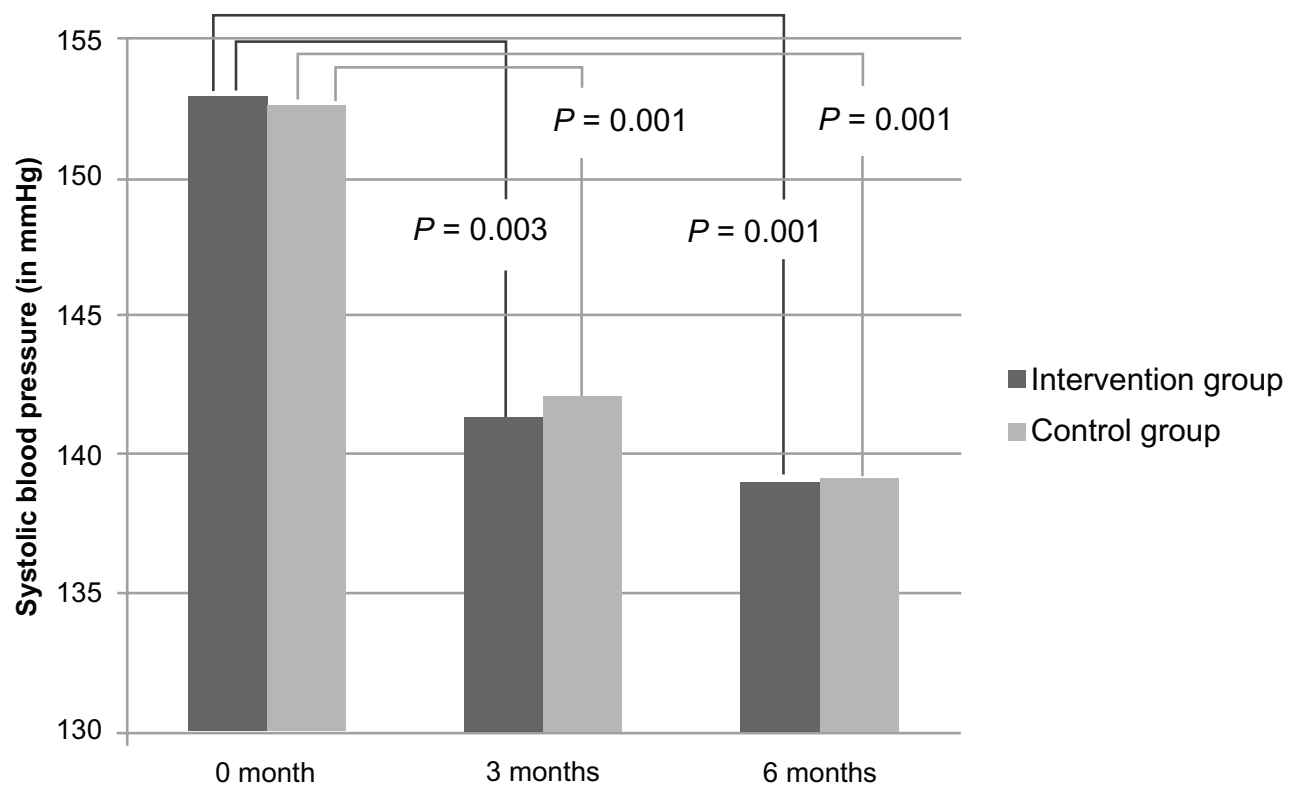

Figure I Evolution of the average systolic blood pressure in both groups at month 0,3 , and 6 .

(control group) ${ }^{25}$ Weight decreased in all three groups but a lifestyle modification program with a maximum of ten consultations over 6 months favored the average weight decrease by $1.6 \mathrm{~kg}$ in the telephone group and by $1.1 \mathrm{~kg}$ in the email group.

\section{$\mathrm{BMI}$}

Only one patient in the ACG and two in the UCG were able to reduce their BMI to below the $25 \mathrm{~kg} / \mathrm{m}^{2}$ target. This result is not surprising, since it has been shown that it is very difficult to moderate BMI by lifestyle interventions only. ${ }^{2,13}$ A multidimensional approach is needed that addresses the multiple determinants of obesity in order to prevent diabetes, hypertension, hypercholesterolemia, and arthritis that, in turn, result in increased cardiovascular morbidity and mortality. ${ }^{3,5}$

\section{WC}

Five ACG participants were able to reduce their WC to below the target compared with only one participant in

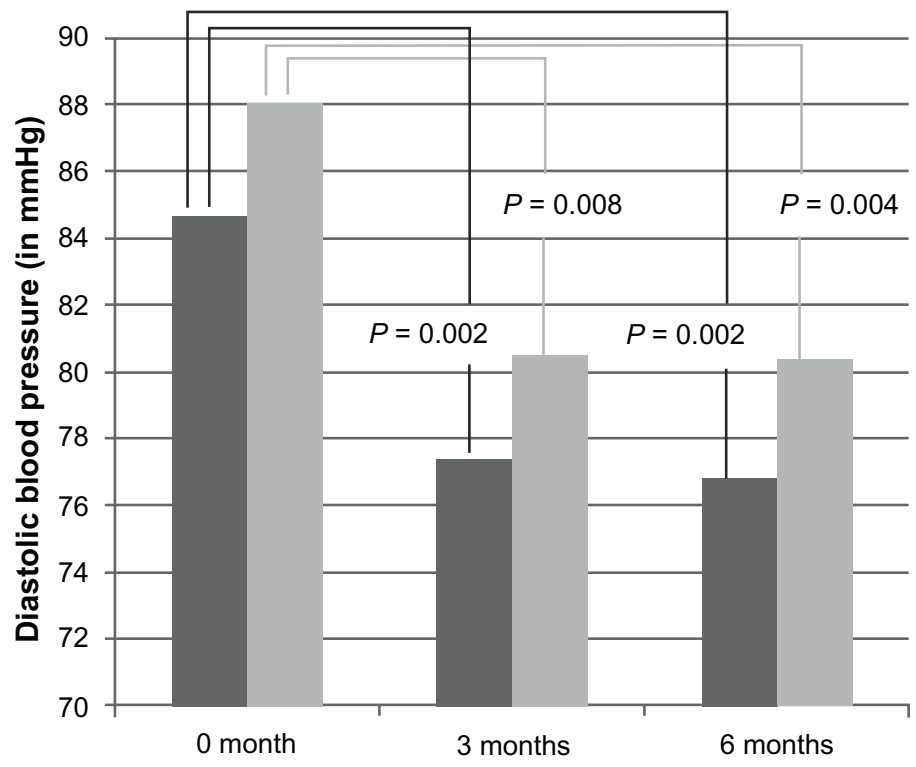

Intervention group

Control group

Figure 2 Evolution of the average diastolic blood pressure in both groups at month 0,3 , and 6 
the UCG. Compared with other European studies, the total proportion of patients achieving the target in our study is remarkably higher. ${ }^{2}$ The decrease in WC in our study is similar to those obtained in a Dutch study. ${ }^{25}$

Reducing WC may have clinical importance, as it is a major cardiovascular risk factor. ${ }^{3}$ Moreover, abdominal fat deposition is an important risk factor for the development of diabetes and various cardiovascular diseases. ${ }^{26}$

\section{Smoking}

Throughout the entire study, no patient stopped smoking, despite a specific emphasis being placed on smoking cessation. A possible explanation is that there were few smokers in both study groups. In the participating practice, serious efforts had previously been made to encourage patients to cease smoking. We did not inquire into the motivation of smokers to cease smoking.

This finding contrasts with a Spanish study that showed that a self-help program on smoking cessation and a single short telephone call increased the success rate. ${ }^{27}$

\section{Blood pressure}

The systolic and diastolic blood pressure decreased in the ACG and the UCG. After 6 months, the results were significant in both groups, but, in the intervention group, the result was already significant after 3 months.

Contrary to the nonsignificant difference between the ACG and the UCG, other studies have shown that encouragement interventions have positive effects on blood pressure among patients at cardiovascular risk. For instance, a study in Toronto, Canada showed a significantly higher decrease in blood pressure in high-risk patients taking part in a twice-weekly telephone conference group compared with control-group patients. ${ }^{21}$ However, in our study, a much larger decrease in blood pressure was observed after 6 months. This is because our study population was older and had higher initial blood pressure.

An important finding of our study is that a decrease of systolic and diastolic blood pressure could be noticed after 6 months in both groups. This can potentially be explained by the Hawthorne effect.

\section{Risk evaluation}

For some individual participants, there was a shift to lower risk, but these shifts were not significant for the entire study group. The shifts to a lower risk group were mainly due to blood pressure decreases, since smoking status did not change and lipid levels were not measured during the study - in view of the other results, it is unlikely that lipids would have changed during the study period.

It is somewhat surprising that participants with an already lower cardiovascular risk were most able to decrease their blood pressure. Thus, it seems more difficult to initiate lifestyle changes among those with a moderate or high cardiovascular risk. This is probably because participants at low cardiovascular risk were already making some effort to decrease their risk and/or they were more susceptible to the interventions.

A Dutch study from 2008 looked at the influence of a web-based health risk assessment with tailored health advice on cardiovascular risk. ${ }^{28}$ The study revealed a significant decrease in cardiovascular risk for the intervention group. In contrast to our study, the risk reduction was mainly observed in the group with the highest Framingham risk.

\section{Limitations}

There are three limitations to this study. First, there were relatively few patients in the $\mathrm{ACG}$ and $\mathrm{UCG}$; despite minimization, the proportion of female patients was eventually lower in the ACG. Second, a larger study group and a longer follow-up might have revealed more significant findings. Finally, determination of lipid levels at the end of the study might have revealed changes in lipid concentrations, allowing for more accurate risk estimation.

\section{Conclusion}

A significant decrease in mean systolic and diastolic blood pressure was observed in the ACG and the UCG. In the ACG, results were already significant after 3 months and, in the UCG, a significant decrease of blood pressure was observed after 6 months. The decrease in blood pressure was mainly observed among participants with low cardiovascular risk. Smoking status, weight, BMI, and WC did not change in either group.

The results of this study demonstrate the need for tailored interventions that encourage in patients increased self-management and empowerment, with the aim to reduce cardiovascular risk factors over a long period. Effective patient empowerment probably requires more behaviorally sophisticated support to increase patient self-management, self-efficacy, and self-esteem.

\section{Acknowledgments}

We would like to gratefully thank all patients who participated in the study and L Stulens and R Huysmans for their support, help, and advice. 


\section{Disclosure}

The authors declare no conflicts of interest in this work.

\section{References}

1. Lloyd-Williams F, O'Flaherty M, Mwatsama M, Birt C, Ireland R, Capewell S. Estimating the cardiovascular mortality burden attributable to the European Common agricultural policy on dietary saturated fats. Bull World Health Organ. 2008;86(7):497-576.

2. Banegas JR, López-García E, Dallongeville J, et al. Achievement of treatment goals for primary prevention of cardiovascular disease in clinical practice across Europe: the EURIKA study. Eur Heart J. 2011;32(17):2143-2152.

3. Graham I, Atar D, Borch-Johnsen K, et al; European Society of Cardiology (ESC); European Association for Cardiovascular Prevention and Rehabilitation (EACPR); Council on Cardiovascular Nursing; European Association for Study of Diabetes (EASD); International Diabetes Federation Europe (IDF-Europe); European Stroke Initiative (EUSI); Society of Behavioural Medicine (ISBM); European Society of Hypertension (ESH); WONCA Europe (European Society of General Practice/Family Medicine); European Heart Network (EHN); European Atherosclerosis Society (EAS). European guidelines on cardiovascular disease prevention in clinical practice: full text. Fourth Joint Task Force of the European Society of Cardiology and other societies on cardiovascular disease prevention in clinical practice (constituted by representatives of nine societies and by invited experts). Eur $J$ Cardiovasc Prev Rehabil. 2007;14 Suppl 2:S1-S113.

4. Robroek SJ, Bredt FJ, Burdorf A. The (cost-)effectiveness of an individually tailored long-term worksite health promotion programme on physical activity and nutrition: design of a pragmatic cluster randomised controlled trial. BMC Public Health. 2007;7:259.

5. Romdhane HB, Damesceno A, Ebraham S, et al. Prevention of Cardiovascular Disease: Guidelines for Assessment and Management of Cardiovascular Risk. Geneva: World Health Organisation; 2007. Available from: http://whqlibdoc.who.int/publications/2007/9789241547178_eng. pdf. Accessed December 29, 2012.

6. Canadian Hypertension Education Program, Campbell N. 2011 Canadian Hypertension Education program recommendations. Can Fam Physician. 2011;57(12):1393-1397.

7. Dahlöf B. Cardiovascular disease risk factors: epidemiology and risk assessment. Am J Cardiol. 2010;105(Suppl 1):3A-9A.

8. Kostis JB. The importance of managing hypertension and dyslipidemia to decrease cardiovascular disease. Cardiovasc Drugs Ther. 2007; 21(4):297-309.

9. Grover S, Coupal L, Kouache M, Lowensteyn I, Marchand S, Campbell N. Estimating the benefits of patient and physician adherence to cardiovascular prevention guidelines: the MyHealthCheckup Survey. Can J Cardiol. 2011;27(2):159-166.

10. Kotseva K, Wood D, De Backer G, et al; EUROASPIRE Study Group. EUROASPIREIII. Management of cardiovascular risk factors in asymptomatic high-risk patients in general practice: cross-sectional survey in 12 European countries. Eur J Cardiovasc Prev Rehabil. 2010;17(5):530-540.

11. Roccatagliata D, Avanzini F, Monesi L, et al; Collaborative Group Risk and Prevention Study. Is global cardiovascular risk considered in current practice? Treatment and control of hypertension, hyperlipidemia, and diabetes according to patients' risk level. Vasc Health Risk Manag. 2006;2(4):507-514.

Vascular Health and Risk Management

\section{Publish your work in this journal}

Vascular Health and Risk Management is an international, peerreviewed journal of therapeutics and risk management, focusing on concise rapid reporting of clinical studies on the processes involved in the maintenance of vascular health; the monitoring, prevention and treatment of vascular disease and its sequelae; and the involvement of
12. Tinghog G, Carlsson P, Lyttkens $\mathrm{CH}$. Individual responsibility for what? - a conceptual framework for exploring the suitability of private financing in a publicly funded health-care system. Health Econ Policy Law. 2010;5(2):201-223.

13. Devroey D, Kartounian J, Vandevoorde J, et al. Primary prevention of coronary heart disease in general practice: a cross sectional population study. Int J Clin Pract. 2004;58(2):130-138.

14. Wood D; Joint European Societies Task Force. Established and emerging cardiovascular risk factors. Am Heart J. 2001;141(Suppl 2):S49-S57.

15. Devroey D, Senesael E, Moerenhout T, Van De Vijver E, Vandevoorde J. Follow-up of a cardiovascular prevention campaign. Cent Eur J Public Health. 2011;19(4):190-196.

16. Chodosh J, Morton SC, Mojica W, et al. Meta-analysis: chronic disease self-management programs for older adults. Ann Intern Med. 2005;143(6):427-438.

17. Deakin T, McShane CE, Cade JE, Williams RD. Group based training for self-management strategies in people with type 2 diabetes mellitus. Cochrane Database Syst Rev. 2005;2:CD003417.

18. World Health Organization. Health Education in Self-Care: Possibilities and Limitations. Report of a Scientific Consultation. Geneva: World Health Organization; 2010.

19. Farrell K, Wicks MN, Martin JC. Chronic disease selfmanagement improved with enhanced self-efficacy. Clin Nurs Res. 2004;13(4):289-308.

20. Krishna S, Boren SA, Balas EA. Healthcare via cell phones: a systematic review. Telemed J E Health. 2009;15(3):231-240.

21. Nolan RP, Upshur RE, Lynn H, et al. Therapeutic benefit of preventive telehealth counseling in the Community Outreach Heart Health and Risk Reduction Trial. Am J Cardiol. 2011;107(5):690-696.

22. Appel LJ, Clark JM, Yeh HC, et al. Comparative effectiveness of weight-loss interventions in clinical practice. $N$ Engl J Med. 2011;365(21):1959-1968

23. García-Lizana F, Sarría-Santamera A. New technologies for chronic disease management and control: a systematic review. J Telemed Telecare. 2007;13(2):62-68.

24. Loukanova S, Molnar R, Bridges JF. Promoting patient empowerment in the healthcare system: highlighting the need for patient-centered drug policy. Expert Rev Pharmacoecon Outcomes Res. 2007;7(3): 281-289.

25. van Wier MF, Ariëns GA, Dekkers JC, Hendriksen IJ, Smid T, van Mechelen W. Phone and email counselling are effective for weight management in an overweight working population: a randomized controlled trial. BMC Public Health. 2009;9:6.

26. Kotseva K, Wood D, De Backer G, De Bacquer D, Pyörälä K, Keil U. EUROASPIRE III: a survey on the lifestyle, risk factors and use of cardioprotective drug therapies in coronary patients from 22 European countries. Eur J Cardiovasc Prev Rehabil. 2009;16(2):121-137.

27. Míguez MC, Becoña E. Evaluating the effectiveness of a single telephone contact as an adjunct to a self-help intervention for smoking cessation in a randomized controlled trial. Nicotine Tob Res. 2008;10(1):129-135.

28. Colkesen EB, Ferket BS, Tijssen JG, Kraaijenhagen RA, van Kalken CK, Peters RJ. Effects on cardiovascular disease risk of a web-based health risk assessment with tailored health advice: a follow-up study. Vasc Health Risk Manag. 2011;7:67-74.

metabolic disorders, particularly diabetes. This journal is indexed on PubMed Central and MedLine. The manuscript management system is completely online and includes a very quick and fair peer-review system, which is all easy to use. Visit http://www.dovepress.com/ testimonials.php to read real quotes from published authors. 